\title{
Human coronavirus 229E encodes a single ORF4 protein between the spike and the envelope genes
} Ronald Dijkman ${ }^{1}$, Maarten F Jebbink ${ }^{1}$, Berry Wilbrink2 ${ }^{2}$ Krzysztof Pyrc ${ }^{1}$, Hans L Zaaijer ${ }^{3}$, Philip D Minor ${ }^{4}$, Sally Franklin ${ }^{4}$, Ben Berkhout ${ }^{1}$, Volker Thiel ${ }^{5}$ and Lia van der Hoek*1

Address: ${ }^{1}$ Laboratory of Experimental Virology, Department of Medical Microbiology, Center for Infection and Immunity Amsterdam (CINIMA), Academic Medical Center, University of Amsterdam, The Netherlands, ${ }^{2}$ Laboratory for Infectious Diseases and Screening, National Institute for Public Health and the Environment, Bilthoven, The Netherlands, ${ }^{3}$ Laboratory of Clinical Virology, Department of Medical Microbiology, Center for Infection and Immunity Amsterdam (CINIMA), Academic Medical Center, University of Amsterdam, The Netherlands, ${ }^{4}$ National Institute for Biological Standards and Controls (NIBSC), Hertfordshire, UK and ${ }^{5}$ Kantonal Hospital St. Gallen, Research Department, St Gallen, Switzerland

Email: Ronald Dijkman -r.dijkman@amc.uva.nl; Maarten F Jebbink -m.f.jebbink@amc.uva.nl; Berry Wilbrink - berry.wilbrink@rivm.nl; Krzysztof Pyrc - k.a.pyrc@gmail.com; Hans L Zaaijer - h.l.zaaijer@amc.uva.nl; Philip D Minor - pminor@nibsc.ac.uk; Sally Franklin - pminor@nibsc.ac.uk; Ben Berkhout - b.berkhout@amc.uva.nl; Volker Thiel - volker.thiel@kssg.ch; Lia van der Hoek* - c.m.vanderhoek@amc.uva.nl

* Corresponding author

Published: 28 December 2006

Virology Journal 2006, 3:106 doi:10.1186/1743-422X-3-106

This article is available from: http://www.virologyj.com/content/3/I//06

This is an Open Access article distributed under the terms of the Creative Commons Attribution License (http://creativecommons.org/licenses/by/2.0), which permits unrestricted use, distribution, and reproduction in any medium, provided the original work is properly cited.

\begin{abstract}
Background: The genome of coronaviruses contains structural and non-structural genes, including several so-called accessory genes. All group Ib coronaviruses encode a single accessory protein between the spike and envelope genes, except for human coronavirus (HCoV) 229E. The prototype virus has a split gene, encoding the putative ORF4a and ORF4b proteins. To determine whether primary HCoV-229E isolates exhibit this unusual genome organization, we analyzed the ORF4a/b region of five current clinical isolates from The Netherlands and three early isolates collected at the Common Cold Unit (CCU) in Salisbury, UK.

Results: All Dutch isolates were identical in the ORF4a/b region at amino acid level. All CCU isolates are only $98 \%$ identical to the Dutch isolates at the nucleotide level, but more closely related to the prototype HCoV-229E (>98\%). Remarkably, our analyses revealed that the laboratory adapted, prototype HCoV-229E has a 2-nucleotide deletion in the ORF4a/b region, whereas all clinical isolates carry a single ORF, $660 \mathrm{nt}$ in size, encoding a single protein of 219 amino acids, which is a homologue of the ORF3 proteins encoded by HCoV-NL63 and PEDV.

Conclusion: Thus, the genome organization of the group Ib coronaviruses HCoV-NL63, PEDV and HCoV-229E is identical. It is possible that extensive culturing of the HCoV-229E laboratory strain resulted in truncation of ORF4. This may indicate that the protein is not essential in cell culture, but the highly conserved amino acid sequence of the ORF4 protein among clinical isolates suggests that the protein plays an important role in vivo.
\end{abstract}




\section{Background}

Coronaviruses (CoVs) are enveloped, plus-strand RNA viruses belonging to the family Coronaviridae [1]. The genomic RNA is $27-32 \mathrm{~Kb}$ in size, capped and polyadenylated. The virions are $80-150 \mathrm{~nm}$ in diameter and have a unique morphology, with extended, petal-shaped spikes that give the virus a crown-like projection (Latin; corona) under the electron microscope [1]. CoVs are classified into three groups based on phylogenetic and serological relationships. Group 1 and 2 consist of different mammalian coronaviruses, whereas bird viruses dominate group 3. All coronaviruses employ a common genome organization where the replicase gene encompasses the 5'-two thirds of the genome and is comprised of two overlapping open reading frames (ORFs), ORF1a and ORF1b. The structural gene region, which covers the 3'-third of the genome, encodes the canonical set of structural protein genes in the order 5'-spike (S) - envelope (E) - membrane (M) and nucleocapsid $(\mathrm{N})-3$ '. Expression of the replicase gene is mediated by translation of the genomic RNA that gives rise to the biosynthesis of two large polyproteins, pp1a (encoded by ORF1a) and pp1ab (encoded by ORF1a and ORF1b using a ribosomal frameshift at the ORF1a/1b junction). Expression of the structural gene region is mediated via discontinuous transcription of subgenomic (sg) mRNAs, a hallmark of coronavirus gene expression. The number of sg mRNAs produced by a particular coronavirus usually exceeds the number of encoded structural proteins and, consequently, coronaviruses are able to express additional, so-called - accessory - genes (formerly called group-specific genes). These genes are interspersed between the structural genes and their number and location varies within coronavirus genomes. The functions of coronavirus accessory proteins are largely unknown, however, reverse genetic analyses of Mouse Hepatits Virus (MHV) and Feline Infectious Peritonitis Virus (FIPV) suggest that they are not required for virus replication [2-4]. Moreover, deletion of MHV and FIPV accessory genes results in attenuation in their respective hosts, indicating that accessory genes represent pathogenicity factors [2-4].

The group 1 coronaviruses can be divided into the two genetic subgroups $1 \mathrm{a}$ and $1 \mathrm{~b}$ [5]. Members of group 1a include canine coronavirus, FIPV, transmissible gastroenteritis virus (TGEV), and ferret enteric coronavirus. Group 1b includes porcine epidemic diarrhea virus (PEDV), human coronavirus NL63 (HCoV-NL63) and human coronavirus 229E (HCoV-229E). All members of group $1 \mathrm{~b}$ encode one or two accessory proteins between the $\mathrm{S}$ and E gene, ORF3 protein for PEDV and HCoV-NL63, and ORF4a and ORF4b proteins for HCoV-229E (Figure 1). The numbering of the ORFs in HCoV-229E is based on Northern blot analysis of sg RNAs [6]. The presence of an additional sg mRNA in HCoV-229E-infected cells (i.e. sg mRNA3) shifts the numbering from ORF3 to ORF4a/b.
However, the location of HCoV-229E ORFs $4 \mathrm{a}$ and $4 \mathrm{~b}$ genes in the genome (i.e. between $\mathrm{S}$ and $\mathrm{E}$ ) and sequence similarities to the group 1b ORF3 genes strongly support the notion that they are homologous. Unfortunately, very little information is currently available about the structure and function of the ORF3 proteins. Several studies have linked the ORF3 protein of PEDV and TGEV to viral infectivity and pathogenicity $[7,8]$. PEDV and TGEV acquire truncated forms of their accessory proteins after extensively passaging in cell culture, and these laboratoryadapted strains, encoding truncated forms of ORF3-proteins, are less pathogenic than the corresponding wildtype strains (Figure 1) [7,8].

HCoV-229E contains two ORFs, ORF4a and ORF4b between the $S$ and $E$ genes (Figure 1). Since both genes share the same sg mRNA (i.e. sg mRNA4), the expression of gene $4 \mathrm{~b}$ would require alternative mechanisms of translation, such as internal entry, leaky scanning, or translational reinitiation of ribosomes. However, comparison of the hydrophobic domains of both ORF4 parts with the single ORF3 homologs indicates that they encode a similar protein [9], suggesting a scenario in which HCoV-229E acquired an out-of-frame insertion or deletion. It should be noted that the origin of full-length genomic sequences of the group $1 \mathrm{~b}$ coronaviruses PEDV and HCoV-NL63 are derived from clinical isolates, CV777 and Amsterdam-1, Amsterdam-057 and Amsterdam-496, respectively. In contrast, the HCoV-229E ORF4a/b sequence [10] and the HCoV-229E full-length genomic sequence [6] has been determined from a cell culture-adapted virus more than 30 years after the initial isolation of $\mathrm{HCoV}-229 \mathrm{E}$ by Hamre and Procknow [11]. We, therefore, hypothesized that HCoV-229E ORFs 4a/b might actually had been a single ORF that was truncated upon adaptation of $\mathrm{HCoV}$ 229E to cell culture.

\section{Results}

\section{Analysis of HCoV-229E cell culture adapted virus}

We first analyzed the ORF $4 \mathrm{a} / \mathrm{b}$ region of VR-740 ${ }^{\mathrm{TM}}$, a cell culture-adapted virus that also originates from the initial $\mathrm{HCoV}-229 \mathrm{E}$ clinical isolate and which was deposited at the American Type Culture Collection (ATCC) in 1973. The ORF4a/b sequence of VR-740 ${ }^{\mathrm{TM}}$ showed an overall $99 \%$ similarity at the nucleotide level with the published sequence of the cell culture-adapted HCoV-229E, and we detected only one single amino acid substitution in each protein (ORF4a protein; aa $94 \mathrm{Y}>\mathrm{D}$, ORF4b protein; aa 36 $\mathrm{F}>\mathrm{L})$. Still, like the cell culture-adapted HCoV-229E, VR$740^{\mathrm{TM}}$ encodes two ORFs between the $\mathrm{S}$ and $\mathrm{E}$ genes (Figure 2).

\section{Analysis of current clinical HCoV-229E isolates}

The apparent identity of the ORF4a/b region in both cell culture-adapted viruses prompted us to elucidate this 


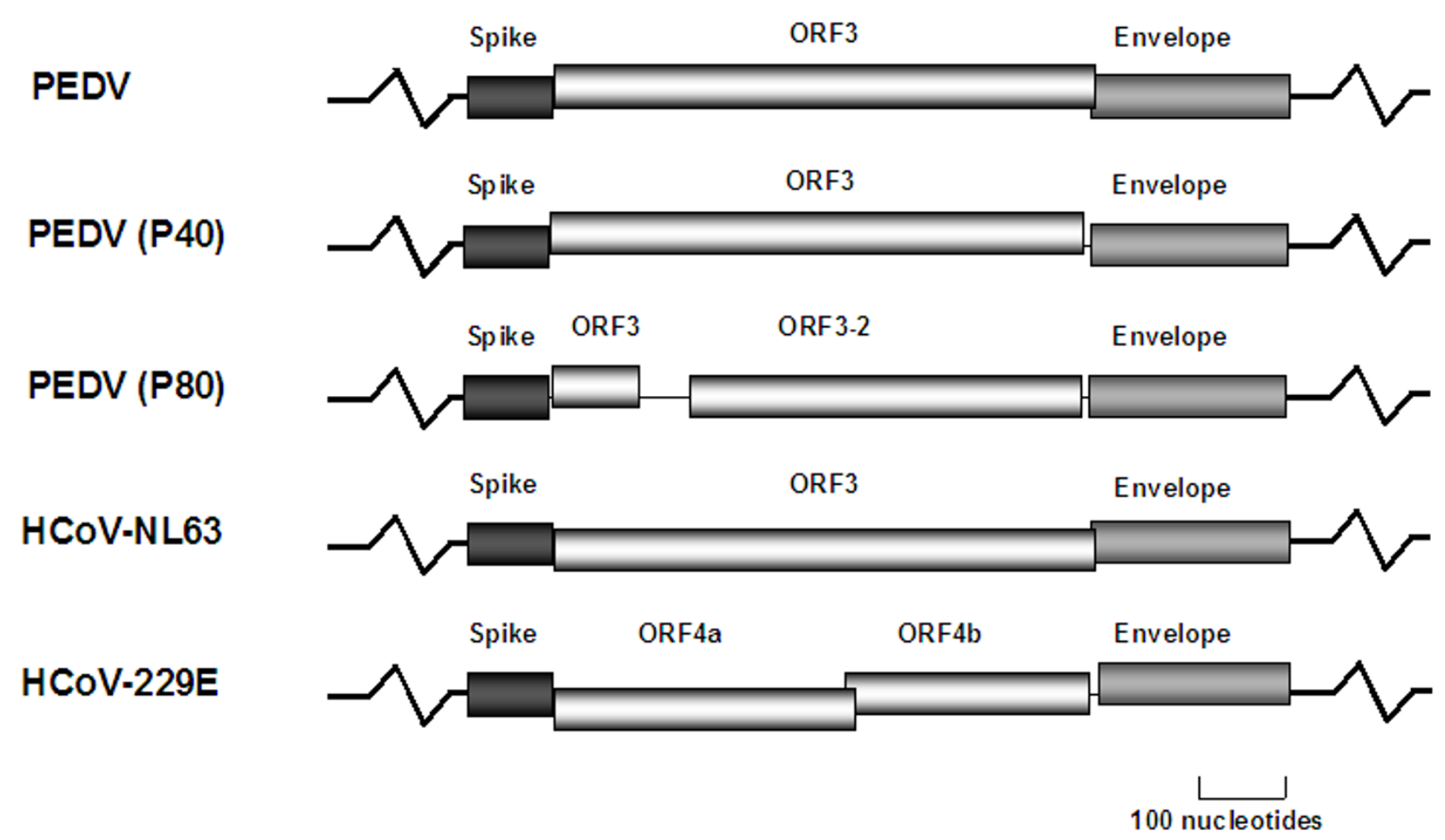

Figure I

Schematic overview of group Ib accessory protein genes between the $S$ and E gene. PEDV (NC 003436), HCoV-NL63 (NC 00583I) and HCoV-229E (NC 002645), the truncated forms of PEDV (P40) and (P80) are based on previous published data [7].

region in clinical HCoV-229E isolates, of which no ORF4a/b sequence data is available thus far. We therefore studied nose/throat swab and nasopharyngeal aspirate materials from 5 patients that were tested positive for HCoV-229E. The clinical symptoms of the HCoV-229Einfected patients were similar to those that are commonly observed for HCoV-229E infections, with symptoms like rhinorrhoea, fever and malaise (Table 1) [12]. RT-PCR sequencing analysis of the ORF $4 \mathrm{a} / \mathrm{b}$ region revealed an overall nucleotide similarity of $97 \%$ of the Dutch clinical isolates to that of the cell culture-adapted viruses. Of most interest is the presence of a 2-nucleotide deletion, within the ORF4a gene of the cell culture-adapted viruses when aligned to the Dutch isolates. Strikingly, this Thymidine and Guanosine deletion at position 395-396 is absent in all clinical isolates. Deduced protein sequences encoded by ORF4a and ORF4b from the published HCoV-229E sequence, the sequence of VR-740 ${ }^{\mathrm{TM}}$, determined in this study, and the sequences of the 5 clinical isolates were aligned. This reveals that clinical isolates encode a single, uninterrupted ORF between the $S$ and E genes (Figure 2). This single accessory gene is 660 nucleotides in length and encodes an ORF4 protein that is 219 amino acids in size, with a high similarity of the $\mathrm{N}$ - and C-terminal domains with ORF4a (93\%) and ORF4b (96\%), respectively. All Dutch sequences have the same amino acid sequence (Figure 2), but some silent mutations were observed at the nucleotide level, excluding the possibility of PCR contamination.

\section{Analysis of early HCoV-229E isolates}

Although our data suggest that the deletion in the laboratory HCoV-229E strain and VR-740 ${ }^{\mathrm{TM}}$ is the result of cell culture-adaptation, we cannot rule out the possibility that the deletion might represent natural variation between different HCoV-229E isolates. Since the VR-740 ${ }^{\mathrm{TM}}$ virus was deposited at the ATCC in 1973, HCoV-229E might have evolved over the years and current clinical isolates may thus differ from the prototype. Alternatively, the Dutch clinical isolates may represent a subgroup of HCoV-229E, and VR-740 ${ }^{\mathrm{TM}}$-like clinical isolates may exist as a second $\mathrm{HCoV}-229 \mathrm{E}$ subgroup. To investigate whether the 2-nucleotide deletion is also present in isolates that are more related to VR-740 ${ }^{\mathrm{TM}}$, we searched for other early $\mathrm{HCoV}-229 \mathrm{E}$ isolates. We were able to retrieve three early isolates that were originally collected at the common cold 


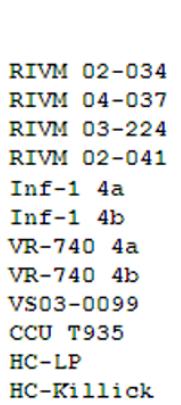

RIVM 02-034 RIVM 04-037 RIVM 03-224 RIVM 02-041 Inf-1 $4 \mathrm{a}$ Inf-1 $4 \mathrm{~b}$ VR-740 $4 \mathrm{a}$ VR-740 4b VS03-0099 CCU T935 HC-LP HC-Killick

RIVM $02-034$ RIVM 04-037 RIVM 03-224

RIVM 02-041

Inf-1 $4 \mathrm{a}$

Inf-1 $4 \mathrm{~b}$

VR-740 $4 a$ VR-740 $4 \mathrm{~b}$ VS03-0099

CCU T935

HC-LP

$\mathrm{HC}-\mathrm{Killick}$

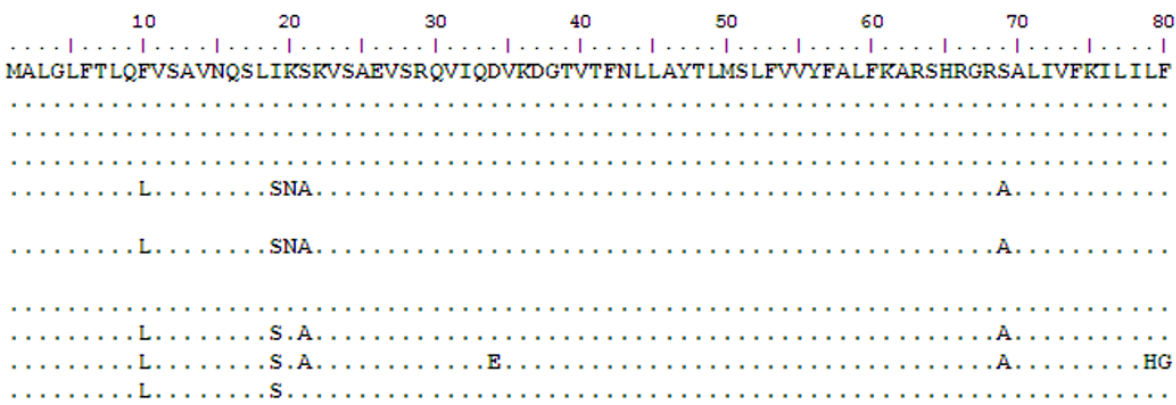

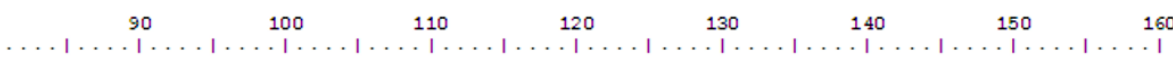
VYVP LLYWSQAYI DAT LIAVI LLGRFFHT AWHCWLYKTWDF IVFNVTT LCYVQGKCWF LENKALKPFVCFYGGDQF LYIG

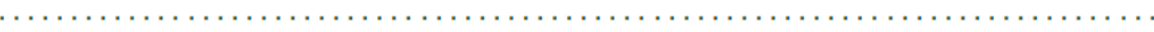

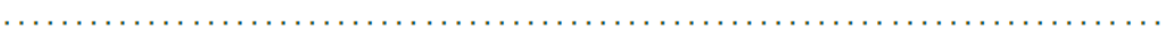

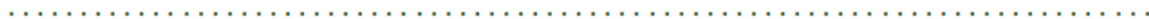

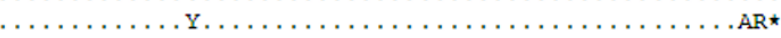

M. .

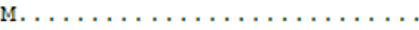

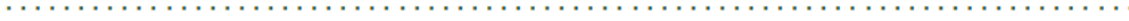

ISLSSM*

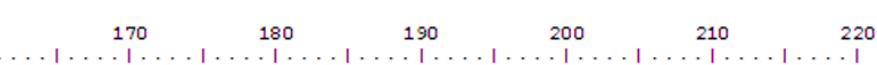

DRIVTYLSTND LYVALRGRIDKDLSLSRKVELYNGECVYLFCEHPAVGIVNTDFKLEIH *

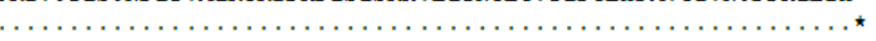

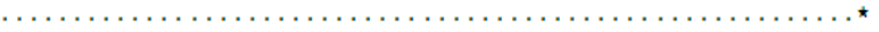

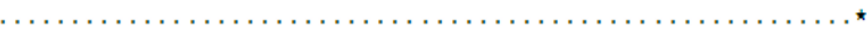

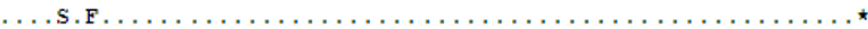

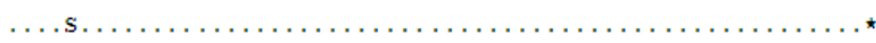

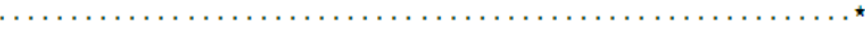

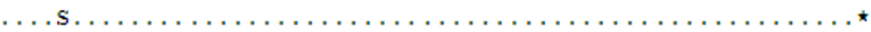

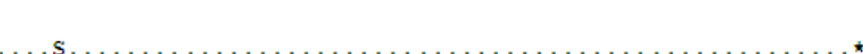

\section{Figure 2}

Amino acid sequence alignment of ORF4 of laboratory-adapted and clinical HCoV-229E strains. "." Denotes identical amino acid to the RIVM 04-037 sequence; "*" denotes stopcodon.

unit (CCU), Salisbury, UK. Two of these are laboratoryadapted viruses of which it is unknown in which extend they were passaged. HC-LP was initially isolated in 1965 [13] and HC-Killick in the eighties [14]. The third sample, CCU-T935, was obtained from an infected person that participated trial T935 in 1986, of which unfortunately all data were lost. Phylogenetic analysis shows that the sequences of ORF $4 \mathrm{a} / \mathrm{b}$ from the three early isolates were indeed more related to the cell culture-adapted, prototype viruses $(98-99 \%)$ than to the current Dutch isolates (98\%) (Figure 2 and 3). Most importantly, however, the early isolate sequences of CCU-T935 and HC-Killick, like those derived from the clinical isolates, do not contain the 2-nucleotide deletion, but carry the uninterrupted ORF between $\mathrm{S}$ and E. Interestingly, HC-LP does not have this particlar 2-nucleotide deletion, instead, a larger (118 nt) deletion was observed that is located halfway the ORF4a region (Figure 2).

\section{Discussion}

Hypothetically, an ORF4b protein could be translated via alternative translation mechanisms, as described for some other coronavirus proteins $[15,16]$, but those mechanisms have not been described for this region, nor has any evidence for the expression of $\mathrm{HCoV}-229 \mathrm{E}$ ORF4b protein ever been reported. In addition, our results show that a large fragment is deleted in the cell-culture adapted HCLP virus, which corresponds with the ORF4b region of the prototype virus. As mentioned previously, it has been shown for MHV and FIPV that accessory genes are dispensable for virus growth in cell culture. Moreover, the deletion of accessory genes resulted in these cases in viruses that are attenuated in vivo. Similarly, attenuation of in 
Table I: Clinical symptoms of HCoV-229E infected patients.

\begin{tabular}{|c|c|c|c|c|c|c|c|c|c|c|c|}
\hline \multicolumn{12}{|c|}{ Symptoms } \\
\hline Patient & Age & $\begin{array}{l}\text { Year of } \\
\text { Sampling }\end{array}$ & $\begin{array}{l}\text { Acute } \\
\text { start }\end{array}$ & Cough & Rhinorrhoea & $\begin{array}{l}\text { Sore } \\
\text { Throat }\end{array}$ & Fever & Malaise & Other & Hospitalized & Diagnosis \\
\hline RIVM 02-034 & 52 & 2002 & Yes & No & Yes & No & No & Yes & Muscle/joint pain & No & ARI, Pharyngitis \\
\hline RIVM 02-04I & 54 & 2002 & Yes & No & Yes & No & Yes & No & Hoarse & No & $\begin{array}{l}\text { Common Cold, } \\
\text { Acute tonsillitis }\end{array}$ \\
\hline RIVM 03-224 & 68 & 2003 & Yes & No & Yes & Yes & Yes & No & $\begin{array}{c}\text { Respiratory } \\
\text { allergy }\end{array}$ & No & Common Cold \\
\hline RIVM 04-037 & 54 & 2004 & Yes & Yes & Yes & Yes & Yes & Yes & - & No & ARI \\
\hline VS03-099* & 81 & 2003 & Yes & Yes & $U$ & $U$ & No & Yes & Dyspnoea & Yes & $\begin{array}{c}\text { Exacerbation of } \\
\text { COPD }\end{array}$ \\
\hline CCU-T935t & $U$ & 1986 & $U$ & $U$ & $\cup$ & $U$ & $U$ & $U$ & $\cup$ & $U$ & $U$ \\
\hline
\end{tabular}

*The person was on treatment for an atypical Mycobacterium infection. tUnfortunately, all administration on Trail No T935 is no longer available. $\mathrm{U}=$ Unknown

$A R I=$ Acute Respiratory infection

COPD = Chronic Obstructive Pulmonary Disease

vivo viral infectivity and pathogenicity has been linked to ORF3 truncation upon in vitro culturing of other group $1 \mathrm{~b}$ coronaviruses. For a virulent PEDV strain this occurred after 40 passages, and more severe truncation and attenuation was observed after 60 or more passages [7]. Similar results have been reported for TGEV after at least 35 passages [8]. Unfortunately, no detailed information is available about the in vitro passaging of the cell cultureadapted $\mathrm{HCoV}-229 \mathrm{E}$ strains. It is tempting to speculate that ORF4 of HCoV-229E, like ORF3 of PEDV, is vital for efficient in vivo replication. The fact that VR-740 ${ }^{\mathrm{TM}}$ contains a truncated ORF4 may explain why this virus replicates in vitro in murine cells expressing HCoV-229E receptor (human CD13), but not in vivo in the human CD13 transgenic animals $[17,18]$. It is of interest to investigate whether an HCoV-229E strain with a more severe truncated or a non-truncated ORF4 gene can replicate in these mice.

Accompanied with the deletions, we also observed several non-silent nucleotide differences between the cell cultureadapted viruses and the clinical isolates. In our Dutch isolates the ORF4 is highly conserved on the protein level. The CCU T935 isolate that was collected in 1986 at the CCU, Salisbury, is a clinical isolate with high ORF4 similarity to the cell culture-adapted viruses. Since we cannot reconstruct the experimental setting performed during the clinical trail T935 at the CCU in 1986, we cannot exclude the possibility that the CCU T935 sample was obtained from a volunteer inoculated with an HCoV-229E laboratory strain. This strain might even have the same origin as the cell culture-adapted viruses [11]. In any case, the CCU T935 sample is derived from an "in vivo" infection, be it experimental or natural, and this further supports a relevant in vivo function of $\mathrm{HCoV}-229 \mathrm{E}$ full-length ORF4 protein. We believe that the divergence between the current Dutch isolates and the early CCU T935 strain most likely represents genetic drift over 20 - 30 years of evolution [19]. Molecular clock analysis with the average mutation rate of coronaviruses $[20,21]$ supports this idea (data not shown). Given the long time of evolution the differences between the CCU T935 and Dutch isolates are remarkably small. For HCoV-NL63 we also observed a highly conserved ORF3 among different clinical isolates [22], and although for PEDV limited sequence data are available, Song et al. found only one nucleotide difference in ORF3 between two PEDV field isolates [7].

Recently, Tang et al. reported on novel bat coronaviruses (Bt-CoVs), of which several cluster with group $1 \mathrm{~b}$ coronaviruses. They determined the full-length genomic sequence of one of these wild-type Bt-CoVs (Bt-CoV/512/ 2005) [23]. The genome organization of this $\mathrm{Bt}-\mathrm{CoV}$ strain is similar to that of the other group $1 \mathrm{~b}$ members, with the exception of one putative gene at the 3 'end of the genome. However, only one accessory protein, encoded by ORF3, is identified between the structural genes $\mathrm{S}$ and $\mathrm{E}$. The ORF3 protein of $\mathrm{Bt}-\mathrm{CoV} / 512 / 2005$ is homologous to ORF3 proteins of PEDV, HCoV-NL63 and the ORF4 protein from our clinical HCoV-229E isolates. These data show that all currently sequenced group $1 \mathrm{~b}$ coronaviruses contain one homologous accessory gene between the $\mathrm{S}$ and E genes.

\section{Conclusion}

We report the first sequences of the ORF4a/b region of clinical HCoV-229E isolates. The experimental data strongly support the hypothesis that a separation of a formerly single ORF4 had taken place upon adaptation of HCoV-229E to cell culture. We observed two different types of deletions, 2 or 118 nucleotides, of the ORF4 gene only in cell culture-adapted viruses whereas all clinical isolates, including CCU T935, encoded a single ORF4 gene. Both types of nucleotide deletion within the ORF4a/ 


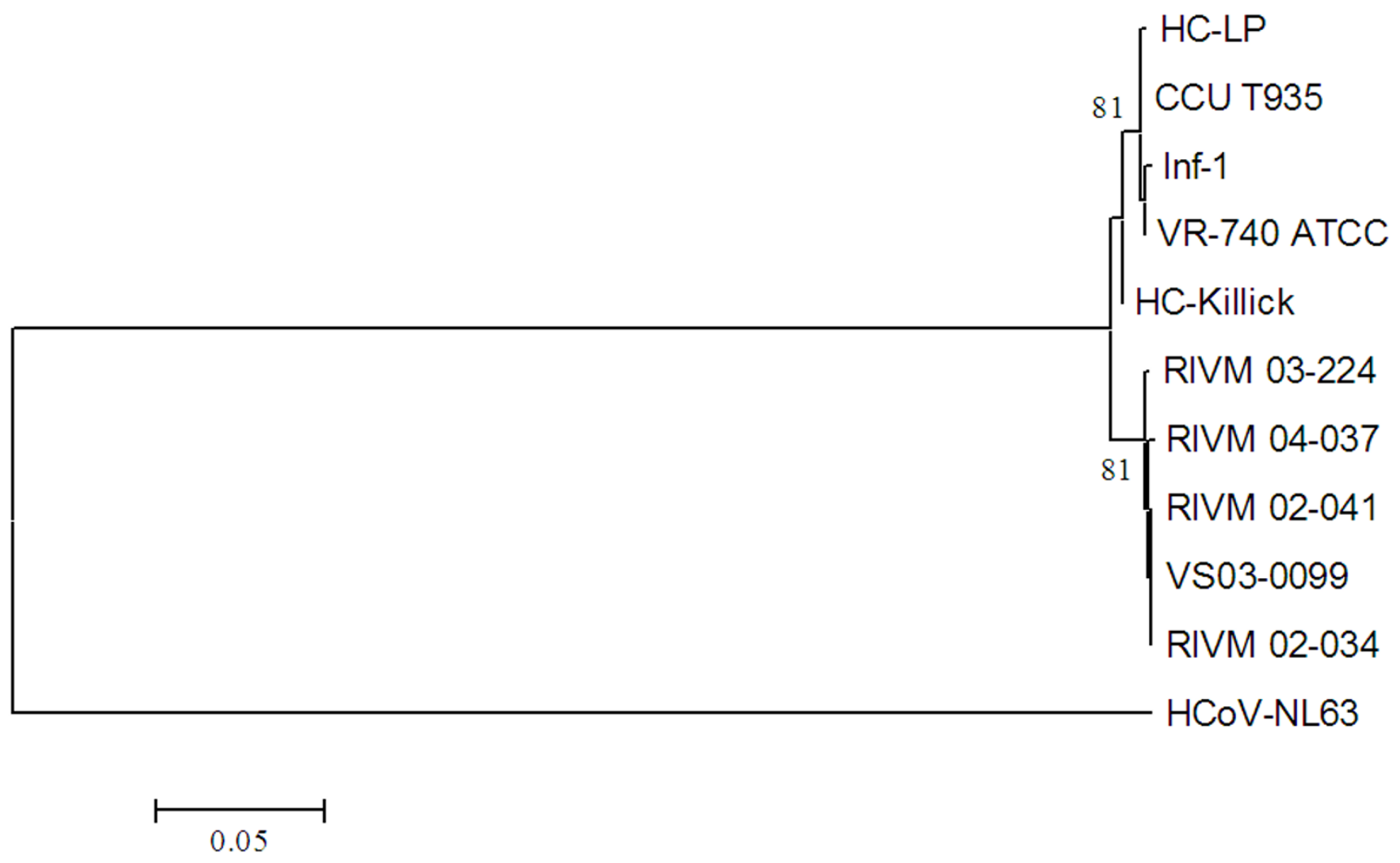

Figure 3

Phylogenetic analyses of ORF4 nucleotide sequences of laboratory-adapted and clinical HCoV-229E strains. ORF3 of HCoV-NL63 (NC_00583I) was used as outgroup; bootstrap values above 70 are shown.

b region of cell culture-adapted $\mathrm{HCoV}-229 \mathrm{E}$ viruses creates a frame shift that introduces an early termination codon, which either separates ORF4 to ORF4a and ORF4b or results in a truncated ORF4(a) fragment (HC-LP). Most likely, the two types of deletion occurred independently and are not site specific. Therefore the genome organization for the group $1 \mathrm{~b}$ coronaviruses (HCoV-NL63, PEDV, $\mathrm{Bt}-\mathrm{CoV}$ and $\mathrm{HCoV}-229 \mathrm{E}$ ) is identical. The amino acid sequence of the HCoV-229E ORF4 protein is highly conserved among clinical isolates suggesting that the protein plays an important role during in vivo infection.

\section{Methods}

\section{Collection of patient material}

Patient materials were collected at the department of Medical Microbiology, Academic Medical Center (AMC), The Netherlands (VS03-099) and from the Laboratory for Infectious Diseases and Screening, National Institute of Public Health and the Environment (RIVM), Bilthoven, The Netherlands (RIVM02-034, RIVM02-041, RIVM03224 and RIVM04-037) (Table 1). One sample was collected in 1986 at the common cold unit (CCU), Salisbury, Great Britain, during Trail no. T935.

\section{Viral RNA isolation}

Total viral RNA was isolated either from $200 \mu$ l cell culture supernatant, $100-200 \mu \mathrm{l}$ nose/throat swab (RIVM) or nasopharyngeal aspirate (AMC) as previously described [24].

\section{RT-PCR}

Reverse transcription and PCR reactions were performed as described $[22,25]$. Amplification of the ORF4a/b region was performed with the primer combination 5'-229EORF4ab (5'-AAC TTC CTT ATT ACG ACG TT-'3) and 3'229E-ORF4ab (5'-ATC CAC TAG CTT AAG GAA CA-'3). If required, a semi-nested PCR was performed with the primers 5'-229E-ORF4abNested (5'-CAT ACA GTA ATG GCT CTA GG-'3) and 3'-229E-ORF4ab, and the cycle profile of the first PCR was modified to 30 cycles.

\section{Sequence analysis of ORF4a/b region}

RT-PCR fragments were directly sequenced with primers 3'-229E-ORF4ab, 5'-229E-ORF4ab, 5'-229EORF4abNested, 5'229E4int (5'-GCA ACT TTG ATT GCT G-'3) and 3'229E4int (5'-GTC CTC TAA GAG CAA C-'3). Sequence reaction was preformed without purifying steps, 
according to the BigDye ${ }^{\circledast}$ terminator V1.1 cycle sequencing manufacturer's protocol on a GeneAmp ${ }^{\circledR}$ PCR System 9700 thermal cycler (Perkin Elmer). Electrophoresis and data collection was performed on a 3100 Genetic Analyzer (Applied Biosystems). Raw collection data was processed and analyzed with Codoncode Aligner v1.52 software (CodonCode Corporation).

\section{Deduced protein sequences}

Deduced protein sequences encoded by ORF4a and ORF4b from the published HCoV-229E sequence (ORF4a; NP 073552, ORF4b; NP 073553), the sequence of VR- $740^{\mathrm{TM}}$, determined in this study, and the sequences of the 5 current and the 3 early isolates were aligned with ClustalX v1.8, and manually adjusted with Bioedit v7.0.1.

\section{Phylogenetic analysis of the ORF4a/b region}

The sequences of the ORF $4 \mathrm{a} / \mathrm{b}$ regions were aligned with ClustalX v1.8 and phylogenetic analyses was conducted with the neighbor-joining method, Kimura distances and a bootstrap of 1000 replicates, using MEGA version 3.1 [26].

\section{Data deposition}

The sequences reported in this paper have been deposited under the Genbank database accession numbers $\underline{\text { EF198671-EF198679. }}$.

\section{Competing interests}

The author(s) declare that they have no competing interests.

\section{Authors' contributions}

RD carried out the viral RNA isolation, RT-PCR, sequencing of RT-PCR fragments and computer analysis. MFJ carried out the design and testing of primers and RT-PCR. BW, HLZ, PDM and SF carried out the collection of the patient material and the clinical data. KP carried out the molecular clock analysis; all authors participated in writing the manuscript. LvdH, BB and VT are the principal investigators.

\section{Acknowledgements}

We thank Stuart G. Siddell from the university of Bristol, United Kingdom, for the kind gift of the HC-LP and HC-Killick samples. The RIVM isolates were collected by the general practitioners from the Continuous Morbidity Registration of the Netherlands Institute for Health Services Research (NIVEL) within the framework of national surveillance of acute respiratory tract infections. R.D. and L.v.d.H. are supported by VIDI grant 016.066 .318 from the Netherlands Organization for Scientific Research (NWO). V.T. received support from the European Commission (SARS-DTV SP22-CT2004-5I I064).

\section{References}

I. Holmes KV, Lai MMC: Coronaviridae: The viruses and their replication. In Fields Virology Third edition. Edited by: Fields BN, Knipe
DM, Howley PM, et al. Philadelphia: Lippincott-Raven Publishers; 1996:1075-1093.

2. de Haan CA, Masters PS, Shen X, Weiss S, Rottier PJ: The groupspecific murine coronavirus genes are not essential, but their deletion, by reverse genetics, is attenuating in the natural host. Virol 2002, 296: I77-189.

3. Herrewegh AA, Vennema H, Horzinek MC, Rottier PJ, de Groot RJ: The molecular genetics of feline coronaviruses: comparative sequence analysis of the ORF7a/7b transcription unit of different biotypes. Virol 1995, 2 I 2:622-63।.

4. Haijema BJ, Volders H, Rottier PJ: Live, attenuated coronavirus vaccines through the directed deletion of group-specific genes provide protection against feline infectious peritonitis. JVirol 2004, 78:3863-387I.

5. Gorbalenya AE, Snijder EJ, Spaan WJ: Severe acute respiratory syndrome coronavirus phylogeny: toward consensus. J Virol 2004, 78:7863-7866.

6. Thiel V, Herold J, Schelle B, Siddell SG: Infectious RNA transcribed in vitro from a cDNA copy of the human coronavirus genome cloned in vaccinia virus. J Gen Virol 200 I, 82: | 273- I 28I.

7. Song DS, Yang JS, Oh JS, Han JH, Park BK: Differentiation of a Vero cell adapted porcine epidemic diarrhea virus from Korean field strains by restriction fragment length polymorphism analysis of ORF 3. Vaccine 2003, 2 I: I833- | 842.

8. Woods RD: Efficacy of a transmissible gastroenteritis coronavirus with an altered ORF-3 gene. Can J Vet Res 200I, 65:28-32.

9. Duarte M, Tobler K, Bridgen A, Rasschaert D, Ackermann M, Laude $H$ : Sequence analysis of the porcine epidemic diarrhea virus genome between the nucleocapsid and spike protein genes reveals a polymorphic ORF. Virol 1994, I 98:466-476.

10. Raabe T, Siddell S: Nucleotide sequence of the human coronavirus HCV 229E mRNA 4 and mRNA 5 unique regions. Nucleic Acids Res 1989, I 7:6387.

II. Hamre D, Procknow J]: A new virus isolated from the human respiratory tract. Proc Soc Exp Biol Med 1966, I 2 I: I90-193.

12. Bradburne AF, Bynoe ML, Tyrrell DA: Effects of a "new" human respiratory virus in volunteers. $\mathrm{Br}$ Med J 1967, 3:767-769.

13. Tyrrell DA, Bynoe ML, Hoorn B: Cultivation of "difficult" viruses from patients with common colds. $\mathrm{Br}$ Med J I968, I:606-610.

14. Myint S, Harmsen D, Raabe T, Siddell SG: Characterization of a nucleic acid probe for the diagnosis of human coronavirus 229E infections. J Med Virol 1990, 3 I: I65-I72

15. Thiel V, Siddell SG: Internal ribosome entry in the coding region of murine hepatitis virus mRNA 5. J Gen Virol 1994, 75(Pt I I):304|-3046.

16. Liu DX, Inglis SC: Internal entry of ribosomes on a tricistronic mRNA encoded by infectious bronchitis virus. J Virol 1992 , 66:6|43-6154.

17. Wentworth DE, Tresnan DB, Turner BC, Lerman IR, Bullis B, Hemmila EM, Levis R, Shapiro LH, Holmes KV: Cells of human aminopeptidase $\mathbf{N}$ (CDI3) transgenic mice are infected by human coronavirus-229E in vitro, but not in vivo. Virol 2005 , 335:185-197.

18. Lassnig C, Sanchez CM, Egerbacher M, Walter I, Majer S, Kolbe T, Pallares $\mathrm{P}$, Enjuanes L, Muller $\mathrm{M}$ : Development of a transgenic mouse model susceptible to human coronavirus 229E. Proc Natl Acad Sci USA 2005, I 02:8275-8280.

19. Chibo D, Birch C: Analysis of human coronavirus 229E spike and nucleoprotein genes demonstrates genetic drift between chronologically distinct strains. J Gen Virol 2006, 87:1203-1208.

20. Vijgen L, Keyaerts E, Moes E, Thoelen I, Wollants E, Lemey P, Vandamme AM, Van Ranst M: Complete genomic sequence of human coronavirus OC43: molecular clock analysis suggests a relatively recent zoonotic coronavirus transmission event. J Virol 2005, 79: 1595-1604.

2I. Sanchez CM, Gebauer F, Sune C, Mendez A, Dopazo J, Enjuanes L: Genetic evolution and tropism of transmissible gastroenteritis coronaviruses. Virol 1992, 190:92-105.

22. Pyrc K, Dijkman R, Deng L, Jebbink MF, Berkhout B, van der Hoek L: Mosaic structure of human coronavirus NL63, one thousand years of evolution. J Mol Biol 2006, 364:964-73.

23. Tang XC, Zhang JX, Zhang SY, Wang P, Fan XH, Li LF, Li G, Dong BQ, Liu W, Cheung $C L$, et al.: Prevalence and genetic diversity of coronaviruses in bats from China. J Virol 2006, 80:748I-7490. 
24. Boom R, Sol C], Salimans MM, Jansen CL, Wertheim-van Dillen PM, van der NJ: Rapid and simple method for purification of nucleic acids. J Clin Microbiol 1990, 28:495-503.

25. Pyrc K, Bosch BJ, Berkhout B, Jebbink MF, Dijkman R, Rottier P, van der Hoek L: Inhibition of HCoV-NL63 infection at early stages of the replication cycle. Antim Ag Chemoth 2006, 50:2000-2008.

26. Kumar S, Tamura K, Nei M: MEGA: Molecular Evolutionary Genetics Analysis software for microcomputers. Comput Appl Biosci 1994, 10:189-191.

Publish with Biomed Central and every scientist can read your work free of charge

"BioMed Central will be the most significant development for disseminating the results of biomedical research in our lifetime. " Sir Paul Nurse, Cancer Research UK

Your research papers will be:

- available free of charge to the entire biomedical community

- peer reviewed and published immediately upon acceptance

- cited in PubMed and archived on PubMed Central

- yours - you keep the copyright

Submit your manuscript here:

http://www.biomedcentral.com/info/publishing_adv.asp 